\title{
Exemplary Teachers' Influence on Their Adolescent Pupils Who Later Became Teachers
}

\author{
Eliezer Yariv $^{1} \&$ Ditza Maskit ${ }^{1}$ \\ ${ }^{1}$ Gordon College of Education, Haifa, Israel \\ Correspondence: Eliezer Yariv, Gordon College of Education, 73 Tchernechovsky Street, Haifa, 35705, Israel.
}

Received: July 19, 2013 Accepted: August 13, 2013 Online Published: October 21, 2013

doi:10.11114/jets.v2i1.244 URL: http://dx.doi.org/10.11114/jets.v2i1.244

\begin{abstract}
There are many possible sources that may influence teachers in the acquisition of professional knowledge and skills throughout their careers. The current study analyzes 26 interviews with Israeli female teachers who reported on exemplary teachers from their past who served as role models regarding class management. Contrary to our initial assumption, the respondents of this study could recall only one or two outstanding teachers, mostly from middle and high school, from among the many teachers who had taught them in the past. The findings present outstanding professionals, those who possess unique and unusual personal and professional qualities in the inter-personal, professional and moral-social dimensions. The discussion analyzes how classroom management practices are recalled and why most of the key teachers appeared early in the lives of the respondents, long before they chose to become teachers and attend teachers colleges.
\end{abstract}

Keywords: teacher, teaching, role-model, classroom management, life histories

\section{Introduction}

\subsection{Teachers' Sources of Knowledge}

What are the sources that help teachers acquire their professional knowledge and skills? What have they contributed to teachers' current practices? During which period in their lives did teachers encounter these sources? Before answering these questions, we want to clarify the broad and vague term "sources of professional knowledge." The term may comprise an endless number of persons (e.g. former teachers), objects (e.g. books, movies), or experiences that have had an influence on a teacher. Such influences may take place during the formal professional preparation and throughout the many years of a teacher's career. Within the limited scope of this study, we limit our definition to educators whom our respondents met during their childhood, adolescence or pre-service preparation. These key figures could be charismatic colleague, talented teachers, charming youth leaders or authoritative lecturers whose actions and personalities still resonate with them after many years. The current study follows Lortie's (1975) insights about the initial acquaintance with the teaching profession that pupils gain by observing their teachers. In this study, we look at former teachers who left unforgettable emotional and professional influences on their pupils who later became teachers themselves.

Recalling and identifying former teachers as "sources" is based on the recognition of their outstanding personal and professional contributions, but who are these key figures? Scholars have long discussed the sources of teachers' knowledge and the kinds of activities that pre-service teachers should experience when learning to teach (Clandinin \& Connelly, 1996; Cochran-Smith \& Lytle, 1999; Hiebert, Gallimore, \& Stigler, 2002; Shulman, 1986, 1987). The discussion focuses on the spheres in which this knowledge is accumulated. Is it situational learning (Putnam \& Borko, 2000) that emerges out of practical, situational experiences? Is it related to structured, episodic, or context-specific experience (Carter, 1990; Clandinin, 1992; Elbaz, 1983)? How can theoretical relevance be generalized and applied in practice (Shulman, 1986, 1987)? The nature of this knowledge has been studied intensively, but less attention has been paid to the human sources of this knowledge. In this study, we explore the impressions made by outstanding professionals on their pupils who later became teachers themselves. Clandinin and Connelly's (1995) coined the metaphor of the professional knowledge landscape that charts the cognitive geographies and territorial provinces of this knowledge. Here we portray these 'landmark' model teachers from two perspectives: a) according to the period in which our respondents encountered these influential 
teachers and b) the unique qualities of these teachers as role models in the eyes of their former pupils.

\subsection{Constructive Developmental Perspective}

The first question explores the timeframe in which our respondents encountered these key figures. Such encounters may occur between the age of four and twenty during the period of formal education. Considering such a long period of life, can we reasonably compare the warm memories of a five year-old child of his kindergarten teacher with a recent encounter with a pedagogic advisor of a twenty-five year-old college student? A theoretical yardstick that may help bridge this gap is provided by Robert Kegan's $(1982 ; 1994)$ Constructive-Developmental Theory. The theory construes the psychological evolution of meaning-systems and the development of consciousness and uses these as analytic tools to examine contemporary culture. Kegan argues that children and adults' development grows out of the idiosyncratic meaning that they construct out of life experiences. The constantly changing inner world reflects the experiences and discoveries they make. Two pupils, who have met the same teacher, may create two different pictures reflecting their needs, understanding of the classroom situation and attitudes about the meaning of learning and teaching.

The crossroad where teachers' unique personality attracts and draws pupils to admire and desire to imitate them involves strong psychological bonding described in psychoanalytic terms as identification. Based on Freud's writings, identification, in its mature form (defined as 'partial' or 'secondary'), is based on the perception of the teacher's unique qualities and the pupil's sense that they have something in common (Laplanche \& Pontalis, 1973). Identification contributes to the development of the ego and later promotes the adoption of the social life and norms of that role model. From a developmental standpoint, youngsters first identify with family member (e.g. parents, older brothers and sisters) and, later, with other influential adults (e.g. teachers, popular singers). Identification probably does not begin before preschool age and is based on a growing understanding and empathy with the motives, attitudes and conduct of parents and educators (DeHart, Sroufe \& Cooper, 2004). This psychological process is influenced by positive relations and communication between children and caretakers (Grusec \& Goodnow, 1994).

In his Constructive-Developmental Theory, Kegan (1994) addresses the concepts of subject-object consciousness. Subject consciousness refers to the self-concept to which the person is attached that makes it impossible to take an objective look (as in early childhood). Object consciousness is also a part of self that grows out of subject consciousness of an earlier stage and allows individuals to detach_themselves from the underlying phenomenon. Admiration for a teacher's warm personality in second grade (subject) may be replaced with a more sober view that "being nice" to pupils may transmit a sense of weakness and elicit discipline problems at college age (object). Here we explore the specific age at which such bonding took place. Did the infatuation occur in childhood, in early adolescence or later?

Kagan, a developmental psychologist by training and a follower of Jean Piaget, believes that humans grow and change over time and enter qualitatively different phases as they grow. In addition to childhood experience, we question whether our respondents encountered such role models in their lecturers and tutors during their formal professional training in the college. One might expect that in teaching, as in other professions, formal training provides students with ample opportunities to meet outstanding professionals who are assigned to teach and socialize them. Once such an acquaintance occurs, it provides them with precious experience that will direct their later career and mark the pivotal developmental role of the college. Lortie (1975), however, argues that teaching is unlike other professions, especially with regards to the long "apprenticeship of observation" in schools. Due to this prolonged acquaintance, students enter college with rather clear ideas regarding what teaching is all about. These ideas are not easily "washed out" and leave little room for new experiences and knowledge provided by the training of the college. Students' careers start abruptly with "reality shock" and dramas and the first few weeks on the job lead novice teachers to fall back on their own resources based on memories and experiences gained during childhood. Hargreaves (2010) argues that such induction offers little hope for innovation and strong prospects for maintaining conservatism.

\subsection{Characteristics of Teachers as Role Models}

What characterizes these teachers as role models that make them so special? In his book, "In Over Our Heads: The Mental Demands of Modern Life," Kegan makes an analogy between our contemporary world as the classroom and the expectations of our culture as the curriculum (Kegan, 1994, p. 5). Kegan goes on to discuss how the multiple and often competing demands of our various life roles as adults, parents, partners, professionals and members of organizations, compose the curriculum of our lives. Such an all-embracing cultural and personal "curriculum" is certainly beyond the scope of this paper. Exploring the footprints that teachers leave on their pupils' souls can be limited to relevant childhood classroom experiences within the 
"apprenticeship of observation" that pupils undergo on the other side of the teacher's desk (Lortie, 1975). If we compare two pupils, a second-grade child and a tenth-grade teenager, we must assume that they have different emotional and cognitive abilities that influence their choice of a teacher as a role model that is influenced by their different experiences, levels of understanding and emotional maturity. With these assumptions in mind, we are in need of an analytic tool that will enable us to compare both points of views. To that end, we overlook professional aspects (e.g. lesson planning, didactic methods) of which young children are unaware and limit our focus to the socializing role of the teacher. Socialization includes articulation of ideas, communication of expectations and modeling, teaching and reinforcing of desirable personal attributes and behaviors. This role imitates the parental role and is already familiar to elementary school children. It refers to the teacher's actions that are aimed at influencing the personal and social attitudes and behaviors of children (Brophy, 2006, 17). Teachers also need to discipline their pupils occasionally and take actions (e.g. punishment) to elicit or compel improved behavior form students who fail to conform to expectations. Teachers' socializing and interpersonal dimensions parallel meaningful relations in the family and elsewhere. We assume that the socializing role of teachers creates emotionally-driven processes that shape pupils' behavior. Such meaningful relations and experiences are recalled vividly even after many years.

The socializing role is manifested in endless daily classroom management practices that are aimed at creating an environment that supports and facilitates academic, social and emotional learning and moral growth (Everston and Weinstein, 2006a; Hammerness, 2011; Wubbels, 2011). Everston and Weinstein (2006a) emphasize four relevant themes: First, the idea that positive teacher-child relationships are at the very core of effective classroom management. Educators repeatedly cite the importance of teachers' characteristics as "warm, responsive, caring and supportive, as well as holding high expectations" (Everston and Weinstein, 2006b, p. 11). Second, classroom management is viewed with regard to its moral and social agenda. Teachers' management decisions affect not only the students' ability to learn, but also their social and emotional development. Third, management strategies often rely on external rewards and punishments that are not optimal for promoting academic, social and emotional growth and self-regulated behavior. Numerous educators voice criticism of coercive, exclusionary methods of discipline. Fourth, in order to create an orderly, productive and supportive environment, teachers must take into account student characteristics, such as age, developmental level, race, ethnicity, cultural background, socioeconomic status and ability. The four themes of classroom management may serve as a theoretical perspective of essential teaching qualities that respondents may refer to, but not necessarily as a "checklist" for the enumeration of specific practices.

\subsection{Research Questions}

In summary, exploring the figures that influence young men and women's thoughts, emotions and career decisions may have an important potential for identifying the elements that shape professional learning. The questions we raise are:

a. When and where did the respondents encounter these figures?

b. Did they encounter any exemplary lecturers and mentors at the teachers college?

c. Who were the exemplary teachers and what examples did they provide regarding their classroom management practices?

\section{Method}

This paper examines the influence of model teachers regarding their classroom management practices on their young pupils who later became teachers themselves. For this purpose, we use life histories based on the apprenticeship of observation. Such qualitative interpretive paradigms (Cohen, Manion \& Morrison, 2011) are research methods that are commonly used to explore initial pre-service expectations (Young \& Erickson, 2011), the construction of trust and accountability (Czerniawski, 2011), identity formation (Furlong, 2013) and key experiences (Meijer, Graaf \& Meirnik, 2011; Yair, 2008).

\subsection{Participants}

The sample included 26 teachers working in pre-schools (15\%), elementary schools (56\%), junior high schools (21\%) and high schools (8\%) in northern Israel. In Israel, as in most worldwide countries, teaching is a feminine profession (Addi-Raccah, 2002) and all our respondents were women. The subjects had an average of more than twelve years of in-service experience and included five novice teachers who had been working for less than three years. About one sixth of the respondents belonged to the Arab sector (most of them Druze teachers). Data collection was based on convenience sampling and efforts were made to reach a heterogeneous population. Over half of the teachers (15) were currently fulfilling the position of 'educator,' e.g. they taught most of the lessons 
and were responsible for the social, academic and personal aspects of their pupils' lives. The remaining 11 respondents were teachers of specific subjects, such as English or Science.

\subsection{Research Tools}

A semi-structured interview was developed especially for this study that included several background questions, followed by questions related to the interviewees' motives and reasons for choosing to become teachers, their family and school experiences and significant others who influenced them to choose teaching as their profession. Finally, they were asked about their college experience, the courses they had studied and the supervision they had received in classroom management. The interview included sections containing closed questions (e.g. details of work experiences), sections with multiple-choice questions (e.g. 'of the five items, which would best define your classroom management style?') and open-ended questions (e.g. 'could you please tell me specifically who among the figures at the college provided you with knowledge, insights and experience in classroom management?'). Probes were used to help clarify the respondents' answers.

\subsection{Procedure}

The development of the research tools was carried out within the framework of two courses on teachers' professional development taught by the first author. The students in these courses were veteran teachers who attended the teachers' college in order to complete their formal academic education. After the first version of the interview was developed and refined, the first group of students was briefed about the requirements of conducting interviews as part of their studies. Then, they watched a live simulation with one of their classmates. The instructor explained the practice of conducting an interview and asked for their comments on its clarity and usefulness. Although the interview lasted for only thirty minutes, many students felt that it was too long. Based on their comments, the instructor conducted another live simulation in the second group, which appeared to be more focused and informative. In the following lesson, both groups were asked to split into pairs, practice an interview and receive some feedback. The detailed transcripts were used by the authors to improve the research tool and develop a data analysis scheme. The interviews were conducted soon after that stage and respondents' answers were recorded simultaneously in writing.

\subsection{Data Analysis}

In the first stage of the data analysis $\left(1^{\text {st }}\right.$ and $2^{\text {rd }}$ research questions), the gender of the model teacher (male/female) and the timeframe in which the respondents encountered that teacher (elementary/middle school/ high school) were categorized. The third research question was analyzed in several consecutive stages. First, the transcribed text was read and reread separately by both authors. Second, certain themes and primary categories, such as "providing encouragement," were freely identified (Shkedi, 2011). Third, these categories were adjusted to the classification of the four themes of Everston and Weinstein (2006b): a) teacher-pupil relations, b) moral and social curriculum, c) the use (or lack of use) of external rewards and punishments and d) the sensitiveness to student characteristics.

\section{Results}

\subsection{Teachers' Characteristics as Role Models}

The first research question dealt with the occasions and age at which the respondents encountered the role models. Most of the respondents (except two) could easily identify certain teachers as role models. Over half of the role models were female teachers (about 58\%), while the male teachers' (42\%) seemed to be over-represented compared to their small representation in the Israeli education system. The majority of our respondents encountered these exemplary figures during high school (about 56\%) and, to a lesser degree, in middle school $(20 \%)$ and elementary school (24\% predominantly in the fifth and sixth grades). The recollection of these teachers as role models occurred mainly during early and middle adolescence. The majority of these exemplary teachers taught subjects such as English and Bible and, unexpectedly, very few were 'educators.' As that position comprises not only teaching subject matter, but also being responsible for pupils' social and personal well-being, it was expected that teachers in that influential position would be represented to a larger degree in the sample (The 'educator' position comprises about one third to one half of the teaching force in Israel, depending on grade level). This means that it is not the formal role that is significant, but rather the personal and professional characteristics of the teachers.

The second research questions explored whether there were teachers whom our respondents encountered during their academic preparation. Only two such figures emerged: one had taught psychology and didactics at the university, while the other was a college teacher with whom the novice respondent worked during her induction period in an elementary school. It appears that the process of psychological identification with teachers and the 
teaching profession does not occur before early and middle adolescence and rarely during academic preparation, at which age pupils become more aware of specific teaching roles (e.g. organizer, instructor and controller).

\subsection{Teachers' Classroom Management Qualities}

The third research question dealt with identifying the characteristics of the exemplary teachers. All participants provided a detailed answer about the behavioral characteristics of the exemplary teachers.

"The teacher I remember as an example... her attitudes, the way she did things, her investment, openness, seriousness, professional knowledge and personality"; "This teacher was an example of how to manage a class. She combined clear demands of the learners and was assertive in her teaching, while establishing personal connections with the learners"; "She reinforced our progress positively and taught us competently, as well as responding to the students' curiosity of the subject under discussion."

Many participants expressed very positive attitudes toward those teachers who had managed to build strong and warm relations and increased their pupils' motivation. The use of the first-person singular emphasized this sentiment: "I learned a lot from her", "I loved to listen to her, even when I was ill, I didn't give up and went to class", "We had so much respect and appreciation for him. We always came to lessons on time and informed him of everything" and "He believed in us all the time and we wanted to prove to him that he was right." Others who used the third person conveyed the same message: "The students were highly motivated, thirsty to study and know more"; "They studied out of interest, not because they had to" and "He respected us, and therefore the respect was mutual."

In general, the findings portray positive and active behavioral characteristics, even when the descriptions refer to lack of deeds and practices of control: "The teacher has never punished us nor raised her voice. Based on the content analysis, the characteristics provided by the respondents' form three major categories; (a) the inter-personal, (b) the professional and (c) the social-value dimensions, as described below:

The inter-personal dimension: Most of the traits mentioned frequently and in strong terms referred to warm student-teacher relations, respect for students and a show of consideration: "He was a very considerate teacher, respected the students and showed good inter-personal communication", "She was a teacher who came to visit us at home very often." The respondents also referred to the teacher's ability to establish a personal relationship with the students: "She was attentive and saw the student" and "She knew how to see me with my needs and difficulties." The respondents emphasized the support and encouragement that they had received: "She was supportive, praising and encouraging," "She used to praise us all the time: how much you know, you're excellent, only praise." Another characteristic frequently described in the inter-personal dimension was related to the teachers' openness toward students as expressed in behaviors such as: "She used to let all the kids participate in choosing and constructing the exam questions", "She never criticized or said that our opinion was right or wrong; everyone could voice his opinion and she would accept it." The phrase "at eye level" was frequently mentioned, clearly pointing to the sense of equality the teacher attained with the students that was an integral element in mastering the skill of class management.

The professional dimension: This was seen in the behavior of the exemplary teachers in terms of didactic skills and broad subject matter knowledge: "An excellent professional teacher", and "He taught us efficiently", "A teacher who was a source of knowledge." Comments also included the teacher's didactic skills and the ability to connect theory with practice: "The didactic courses were accompanied by examples from the field which were relevant to the issues under discussion: "In the second year, when I'd already started working in school, I can say that, in these lessons, I actually saw how what I had learned was translated into practical behavior in class". Other comments reflected the teacher's ability to promote the students' acquisition of knowledge through experience: "While teaching the Bible stories, she used appropriate intonation in a dramatic manner, changing her facial expressions according to the text when reading a biblical or a literary paragraph." Managing to arouse interest and motivation was also mentioned: "The teacher was fascinating and we studied out of interest". Respondents also appreciated teachers who connected studies to the students' world: "I remember that the teacher caught the learners' curiosity". Injection of humor was another method that was mentioned: "She knew how to integrate a sense of humor with teaching and introduced a great deal of interest into the lessons." Several respondents mentioned their admiration for the teacher's strong authoritative personality: "presenting clear requirements of the students", "She was authoritative" and "He spoke in a low tone of voice."

Many of the exemplary teachers' seemed to succeed in being simultaneously authoritarian and considerate. The combination of these two qualities served, according to the participants, as a good formula for success in the domain of class management. "The teacher knew how to listen, to help, to smile and to be angry when he had to be." "He gave an example of managing a class by integrating clear demands of the learners with assertiveness in 
teaching through establishing personal relationships with the learners," and "Authoritarian, but showing a sense of humor."

The social-value dimension: Only a few participants described model teachers who transmitted moral values and provided personal examples, especially in tense situations: "She didn't deal just with academic matters and teaching material for the matriculation exams. What was important was that we should be good citizens with values for a better, considerate, helping and supportive society."

\subsection{Good Examples at the College Level}

After being asked a general question about an exemplary teacher, the respondents were probed to recall a specific instructor or mentor who left unforgettable memories regarding classroom management. This question resulted in very few positive responses and only one third of the respondents mentioned such a figure, such as a pedagogical advisor who accompanied students in the school during the practical teaching experiences, an educational consultant and the like. Only one participant stated that, "All the teachers at the college, each contributed his part, his knowledge and experience in his own field." More than half of the respondents could not pinpoint any significant instructor or tutor and the tone of their answers clearly explained the reasons: "She didn't provide us with knowledge, insights and experience in managing a class", "There is no such figure I can point to during my studies in college", "I don't remember much", and, simply, "I don't remember." Other answers emphasized the gap between the actual reality in which managing a class occurred as a significant component of training and the time that had elapsed since then. Some respondents mentioned the many years that had passed since their initial professional training as an explanation, while others mentioned that the subject of classroom management was not studied much. These explanations can be easily refuted if we consider the warm statements about the exemplary teachers who had taught the same respondents during their elementary and high school years.

Interestingly, the few exemplary teachers that the participants recalled during their college years made their impact in the inter-personal and the professional dimensions, and not in the moral dimension. For example, some said that the instructor knew "how to solve problems in every field", "to give wise advice" and "to accept each and every student." Regarding the professional dimension, the participants indicated that the exemplary teachers had professional knowledge in the field of teacher training, as well as in that of class management: "She was serious and had a lot of knowledge about education and in dealing with a class", "She was the one from whom I've learned the most and acquired the greatest amount of knowledge", "She was an expert in her field", "She knew very well how to manage a class." in relation to class management, comments were "It is not the knowledge she taught me, but the way in which she managed the class". Using helpful teaching strategies, such as "giving examples from the field", "providing tools for working and coping with classes", and "making the practical experience period into a good experience", was also mentioned. These elements were demonstrated through "actual assistance", "providing help" and "developing the learner." We summarize by stating that the exemplary teachers in the college were characterized by, in the respondents' words, an "educational approach", "leadership skills", an ability to "make the subject matter attractive for the students", "providing feedback" and offering "an opportunity for actual experience."

In summary, the findings portray outstanding professionals who possess unique and unusual personal and professional qualities in the inter-personal, professional and moral-social dimensions. Most of the respondents could recall only one or two teachers from among the many teachers who had taught them, the majority in elementary and junior high school. Contrary to our initial assumption, the period of training in the teachers college left only a few memories of outstanding teachers.

Table 1. Role model teachers' characteristics: Main findings

\begin{tabular}{ll}
\hline Role model teacher & characteristics \\
\hline Gender & Relatively equal share among female (58\%) and male teachers (42\%) \\
School level & Mostly high school teachers $(58 \%)$, some middle school and elementary school \\
& only two outstanding teachers taught in Higher education institution \\
Role at school & Mostly subject matter teachers, very few "educators" \\
Professional qualities & Unusual personal and professional qualities in the inter-personal, professional and \\
& moral-social dimensions. \\
\hline
\end{tabular}

\section{Discussion}

Memories of schooling are essential for the development and practice of teachers and may become venues for understanding and insight. The meanings of these memories for the understanding of decisions of young people to become teachers have theoretical and practical significance. Memories of exemplary and non-exemplary teachers 
include themes of academic challenges and successes, failures and humiliations, competition and fairness, assessment and transitions (Rothenberg, 1994). That is the personal and cultural curriculum described by Kagan: "the expectations upon us...demand something more than mere behavior, the acquisition of specific skills, or the mastery of particular knowledge. They make demands on our minds, on how we know, on the complexity of our consciousness" (Kegan, 1994, p. 5). Although one may argue that teachers are influenced in their work mainly by organizational and structural aspects (Jordell, 1987), we focus here on the human factor.

The encounter with influential personalities occurred mainly during the early and middle adolescent period of the respondents' educational history, a period in transition from childhood to adulthood when, in Kegan's (1994) terms, they still enjoyed a "subject" naïve perspective combined with a more sober "object" perspective of the adults who socialize them. These impressions were formed through a strong psychological bonding, an identification that reflects the perception of the teachers' unique qualities and the pupils' perceptions that they have something in common (Laplanche \& Pontalis, 1973). The identification found here refers to general personal qualities, as well as specific traits and practices. It seems that adolescence is an age when pupils are open to infatuation with a role model in general, as well as being able to perceive the small gestures and nuances of that model. May be at that age, long before beginning their formal professional preparation that youngsters begin to seriously consider choosing the teaching profession.

Contrary to our initial assumption, we ask why studies at the teachers college left only a few memories of outstanding teachers. After all, professional training provides students with their first opportunity to become acquainted with expert lecturers and practitioners and to experience the realities of the profession together with them. These outstanding figures are assigned to teach and socialize students during the practicum period in which they work closely together. Despite this intimate experience, very few respondents actually recalled any exemplary mentors. Two complementary explanations may account for this. From a developmental standpoint, children and adolescents seem to be highly sensitive and open to external influences (Pianta, 1997). The years between six and fourteen, middle childhood to early adolescence, are a time of important developmental progress that establishes children's sense of identity. In early adulthood, young people are probably less susceptible to developing impressions of key figures. For example, Yair (2008) and his students who collected about 3,000 personal stories of "key-educating-figures" who left an unforgettable life-changing impact, found that about 12 percent of the retrospective key experiences were related to the elementary school period, 27 percent to the junior and senior high school period and only 12 percent to the higher educational period. In Yair's research, other experiences emerged from various encounters, such as informal educational settings (17\%), family (8\%) and army duty $(10 \%)$. As surprising as it may seem, it appears that influential and outstanding classroom managers are seldom encountered in teacher training programs. Jones (2006) discusses the poor classroom management skills of lecturers in American colleges and lists twelve different factors to account for it, including a lack of experience in recent teaching in public schools by the lecturers, as well as their lack of knowledge in teachers' educational programs. In his meta-analysis and in similar findings in Israel (Ben-Peretz et al., 2011; Gal, 2006), it was found that lecturers and pedagogical advisors lacked substantial skills in classroom management. Interestingly, the contribution of the key figures recalled by respondents was related more to the professional and inter-personal dimensions than to the moral and social dimension.

\subsection{Outstanding Professionals}

The common denominator for all key figures mentioned was related to their unique personal and professional qualities. The interviewees recalled not only the teachers' personalities and charisma, but also their leadership and class management styles. They were impressed by their ability to create an environment that supported and facilitated both academic and social-emotional learning (Everston \& Weinstein, 2006b, 3). These exemplary teachers often dared to go against the stream. They used their own intuition and consciousness, invested much time in developing relations with their pupils and exhibited excellent command of knowledge and pedagogical skills. Interestingly, their outstanding classroom management and leadership skills seemed to blend in with many other qualities. Analyzing their personal qualities along the inter-personal, professional and moral-social dimensions shows that the ability to manage classes combines all three aspects. The exemplary teachers used various tools simultaneously to hold their pupils' attention, to transmit moral values, to interact with pupils and to serve as social leaders. They appear to have had outstanding communication skills that helped them radiate human, as well as professional, qualities. Such personal qualities were met with mutual love, respect and cooperation by their students. From the distance of many years, these teachers' admiring pupils, who later became teachers themselves, still recall the enthusiasm that was inspired in them. McCombs (2009) explains their magic touch:

It is vital for learners that they be at the center of the educational process from their perspective as whole persons with social, emotional, physical, motivational, intellectual and spiritual capacities and needs 
during any learning process. It is essential to align the assumptions and principles of education with respect for the learner as an agent with natural learning and motivational capacities (p. 658).

The respondents' descriptions tended to emphasize the positive aspects of the key figures' classroom management skills: an ability to attract the pupils and to create close and warm relations with them. Memories related to the use of power, authority and manipulation were not mentioned. Exemplary teachers built relations of trust and equality, elements that are repeatedly mentioned in studies on exemplary teachers who place much importance on trust in order to increase their students' achievements (Hargreaves \& Shirley, 2008; Pantic, \& Wubbels, 2012). Due to trusting relationships and feelings of respect for their exemplary teachers, students were willing to invest their time and effort in acquiring and understanding new subject matter material and to refrain from interruptions. The three categories found here only partially overlap with Everston and Weinstein's (2006b) four main themes of classroom management. It appears that the youngsters then were impressed by various professional qualities not necessarily similar to the formal definitions used in the literature.

\subsection{A Rare Phenomenon}

Why could our respondents recall only a few exemplary figures? The immediate answer that comes to mind is that pupils encounter dozens of teachers during their school years. Only a few leave unique memories that are not 'washed-out' when new experiences and persons are encountered. Another line of thought is raised by Jordell (1987), who examined the role of teachers' socialization with reference to personal and structural influences. Using teachers' own recollections of experiences as pupils in schools and as students in teachers colleges, Jordell argues that the structural influences at the classroom level, which are determined by structures at the institutional and societal levels, are of major importance. Despite an overwhelming desire to support, care for and relate deeply to pupils, teachers are continually constrained by the conditions in which they work. The prevailing school culture seems to be preoccupied with caution (Barth, 1990). Time is 'stolen' from them by the nature of the current education system, the fragmented and rigid curriculum, the poor nature of their working conditions, the bureaucracy of modern education, the large numbers of pupils and the low frequency of contact. The moral model available for students becomes degraded and their needs remain unmet (Cooper, 2004). Jordell (1987) warns that the influence of persons in the system should not be overestimated and that experiences as a pupil and as a student in a teachers college probably have a rather limited impact.

Is it a matter of personal choice when teachers' organizational role enables them to spend more quality time with their pupils? Despite the existing role division that prevails in the Israeli school system between "educators", the all-inclusive mother-like figure, and teachers of specific subject matter, our respondents mentioned various kinds of teachers, not necessarily those who were assigned the "educator" position. Is it a matter of gender? Not necessarily. The respondents, all of whom were women, selected 42 percent of male teachers as key figures.

\subsection{Limitations and Recommendations}

This exploratory qualitative study reveals that the essence of classroom management skills starts to develop long before student teachers begin their studies at the university. The findings here enable us to map the qualities and timing when these charismatic teachers first appeared in their pupils' lives whose memories are still alive after many years. However, several questions remain to be answered: Why were so few key figures remembered? Is classroom management perceived and recalled as an essential, but hidden ingredient, a necessary condition for good teaching? Why were there so few exemplary teachers in the college years? These findings, which are based on a relatively small sample call for a large-scale quantitative study that would map the influencing factors, what students and teachers actually learn and what the sensitive periods are in which pupils are most likely to be influenced. Such an inquiry would do much to reveal the hidden elements underlying successful classroom management.

\section{References}

Addi-Raccah, A. (2002). The feminization of teaching and principalship in the Israeli educational system: A comparative study. Sociology of Education, 75(3), 231-248.

Brophy, J. (2006). History of research on classroom management. In C. M. Evertson \& C. S. Weinstein (Eds.), Handbook of classroom management: Research, practice, and contemporary issues (pp. 17-43). Mahwah, NJ: Lawrence Erlbaum Associates.

Barth, R. (1990). A personal vision of a good school. Phi Delta Kappan, 71(7), 327-343.

Ben-Peretz, M., Eilam, B., \& Landler-Pardo, G. (2011). Teacher education for classroom management in Israel:

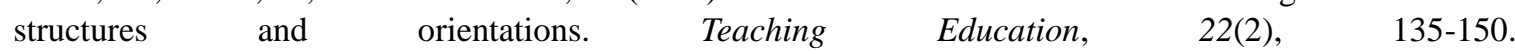
http://dx.doi.org/10.1080/10476210.2011.567842 
Carter, K. (1990). Teachers' knowledge and learning to teach. In W. R. Houston (Ed.). Handbook of research on teacher education (pp. 291-310). New York: Macmillan.

Clandinin, D. J. (1992). Learning to live new stories of practice: Restorying teacher education. Phenomenology and Pedagogy, 9, 70-77.

Clandinin, D. J., \& Connelly, M. E. (1996). Teachers' professional knowledge landscapes: Teachers' stories. Educational Researcher, 25(3), 24-31.

Clandinin, D. J., \& Connelly, F. M. (1995). Teachers' Professional Knowledge Landscape. New York: Teachers College Press.

Cochran-Smith, M., \& Lytle, S. (1999). The teacher research movement: A decade later. Educational Researcher, 28(7), 15-25.

Cohen, L., Manion, L., \& Morrison, K. (2011). Research Methods in Education ( $7^{\text {th }}$ ed.). London: Routledge.

Cooper, B. (2004). Empathy, interaction and caring: Teachers' roles in a constrained environment. Pastoral Care in Education, 22, 12-21. http://dx.doi.org/10.1111/j.0264-3944.2004.00299.x

Czerniawski, G. (2011). Emerging teachers, emerging identities: Trust and accountability in the construction of newly qualified teachers in Norway, Germany and England. European Journal of Teacher Education, 34(4), 431-447. http://dx.doi.org/10.1177/0892020612445685

DeHart, G., Sroufe, L. A., \& Cooper, R. (2004). Child development: Its nature and course (5 ${ }^{\text {th }}$ ed.). New York: McGraw-Hill.

Elbaz, F. (1983). Teacher thinking: A study of practical knowledge. London: Croom Helm.

Evertson, C. M., \& Weinstein, C. S. (2006a). Handbook of classroom management: Research, practice, and contemporary Issues. Mahwah, NJ: Lawrence Erlbaum Associates.

Evertson C. M., \& Weinstein, C. S. (2006b). Classroom management as a field of inquiry. In C. Evertson \& C. Weinstein (Eds.). Handbook of classroom management: Research, practice and contemporary Issues (pp. 3-15). Mahwah, NJ: Lawrence Erlbaum Associates.

Furlong, C. (2013). The teacher I wish to be: Exploring the influence of life histories on student teacher idealized identities. European Journal of Teacher Education, 36(1), 68-83.

Gal, N. (2006). The role of practicum supervisors in behavior management education. Teaching and Teacher Education, 22, 377-393. http://dx.doi.org/10.1016/j.tate2005.11.007

Grusec, J. E., \& Goodnow, J. J. (1994). Impact of parental discipline methods on the child's internationalization of values: A reconceptualization of current points of view. Developmental Psychology, 30, 4-19.

Hammerness, K. (2011). Classroom management in the United States: A view from New York City. Teaching Education, 22, 151-167. http://dx.doi.org/10.1080/10476210.2011.567844

Hargreaves, A. (2010). Presentism, individualism and conservatism: The legacy of Dan Lortie's Schoolteacher: A sociological study. Curriculum Inquiry, 40(1), 143-154. http://dx.doi.org/10.1111/j.1467-873x.2009.

Hargreaves, A., \& Shirley, D. (2008). Beyond standardization: Powerful new principles for improvement. Phi Delta Kappan, 90(2), 135-143.

Hiebert, J., Gallimore, R., \& Stigler, J. (2002). A knowledge base for the teaching profession: What would it look like and how can we get one? Educational Researcher, 31(5), 3-15.

Kegan, R. (1982). The evolving self: Problem and process in human development. Cambridge, MA: Harvard University Press.

Kegan, R. (1994). In over our heads: The mental demands of modern life. Cambridge, MA: Harvard University Press.

Jones, V. (2006). How do teachers learn to be effective classroom managers? In C. Evertson \& C. Weinstein (Eds.). Handbook of classroom management: Research, practice and contemporary issues (pp. 887-907). Mahwah, NJ: Lawrence Erlbaum Associates.

Jordell, K. (1987). Structural and personal influences in the socialization of beginning teachers. Teaching and Teacher Education, 3(3), 165-177.

Laplanche, J., \& Pontalis, J. B. (1973). The language of psychoanalysis. London: The Hogarth Press. 
Lortie, D. (1975). Schoolteacher: A sociological study. London: The University of Chicago Press.

McCombs, B. L. (2009). Commentary: What can we learn from a synthesis of research on teaching, learning and motivation? In K. R. Wentzel \& A. Wigfield (Eds.). Handbook of motivation at school (pp. 655-670). New York: Routledge.

Meijer, P. C., Graaf, G., \& Meirnik, J. (2011). Key experiences in student teachers' development. Teachers and Teaching: Theory and Practice, 17(1), 115-129. http://dx.doi.org/10.1080/13540602.2011.538502

Pantic, N., \& Wubbels, T. (2012). Teachers' moral values and their interpersonal relationships with students and cultural competence. Teaching and Teacher Education, 28(3), 451-460. http://dx.doi.org/10.1080/13617672.2012.650030

Pianta, R. (1997). Adult-child relationship processes and early schooling. Early Education \& Development, 8(1), 11-26.

Putnam, R. T., \& Borko, H. (2000). What do new views of knowledge and thinking have to say about research on teacher learning? Educational Researcher, 29(1), 4-15.

Rothenberg, J. J. (1994). Memories of schooling. Teaching and Teacher Education, 10(4), 369-379.

Shkedi, A. (2011). The meaning behind the words: Methodologies of qualitative research: Theory and practice. Tel Aviv: Ramot, Tel Aviv University Press.

Shulman, L. S. (1986). Those who understand: Knowledge growth in teaching. Educational Researcher, 15(2), 4-31.

Shulman, L. S. (1987). Knowledge and teaching: Foundations of the new reform. Harvard Educational Review, 57(1), 1-22.

Yair, G. (2008). Key educational experiences and self-discovery in higher education. Teaching and Teacher Education, 24(1), 92-103.

Young, J., \& Erickson, L. (2011). Imagining, becoming and being a teacher: How professional history mediates teacher educator identity. Studying Teacher Education, 7(2), 121-129. http://dx.doi.org/10.1080/17425964.2011.591133

Wubbels, T. (2011). An international perspective on classroom management: What should prospective teachers learn. Teaching Education, 22(2), 113-131. http://dx.doi.org/10.1080/10476210.2011.567838

\section{$(\mathrm{cc}) \mathrm{BY}$}

This work is licensed under a Creative Commons Attribution 3.0 License. 